\title{
Correlation between the altmetrics attention score and the citation count: a study based on highly cited breast cancer articles
}

\author{
P. K. Jayasekera ${ }^{1}$, K. S. Abu ${ }^{2}$
}

\begin{abstract}
Measuring the impact of a research publication is a vital factor in the scholarly world. Citation count is a single dimension of measuring the impact of a scholarly publication. However, the evolution of the Internet has changed the ways of accessing research publications and research communication. As a result of the Internet, altmetric became a popular tool to measure the research impact. The objective of the article is to identify the correlations between Citation Count and Altmetrics Attention Score based on the top 100 highly cited articles available in the Web of Science database. The scholarly publications related to breast cancer published in 2014 were selected as the target population. Web of Science database was used to collect the bibliographic information and citation count of the highly cited articles. The keyword "Breast Cancer" was used in the 'title' field of WoS and the search was limited to open access journal articles. The search results were arranged according to the times cited from highest to lowest and ranked according to the citation count. The articles within the top 100 rankings according to the citation count were selected as the sample of this study. Altmetrics bookmarklet was used to collect the Altmetrics Attention Scores of the selected articles. Data were analyzed using SPSS 20 software and Microsoft Excel. Spearman's rank order correlation coefficient was used to determine the relationship between Citation Count and Altmetrics Attention Score. The study revealed that there is a positive correlation $\left(\mathrm{r}_{\mathrm{s}}=.552, \mathrm{p}<0.01\right)$ between the Citation Count and the Altmetrics Attention Score.
\end{abstract}

Keywords: Altmetrics, Breast cancer, Citation Count, Highly cited articles, Research impact, Spearman's rank order correlation coefficient

\footnotetext{
${ }^{1}$ Senior Assistant Librarian, Main Library, University of Ruhuna, Email: kanchana@,lib.ruh.ac.lk iD https://orcid.org/0000-0002-9033-1107

${ }^{2}$ Assistant Professor, Central University of Punjab, India. Email: abumutd@gmail.com
} 


\section{Introduction}

The evolution of the Internet has paved new ways of accessing research outputs, accelerating research communications and enabling collaboration among peer groups. Correspondingly, in the digital era, scholarly journals have also undergone changes by breaking the whole journal into individual units of articles for the purpose of traceability and retrieval (Melero, 2015). A customary tradition for evaluating scholarly communication was merely based on citation-based metrics and peer review (Zahedi, Costas, \& Wouters, 2014). Some of the tools of citation-based metrics are citation counts, normalized citation impact measures, publications in top citation percentiles, journal metrics, h-index and so on. Although citations address scientific impact, they also exhibit high limitations on their way of evaluating the quality of publications (Bornmann \& Leydesdorff, 2013; Martin \& Irvine, 1983). Moreover, the accumulation of citations can take a very long time and they can also be manipulated by means of self-citations (Trueger et al., 2015). Further, citation-based metrics can offer only a single dimension of the scholarly impact of a researcher and also considered as poor indicators of practical impact especially in clinical medicine (Fenner, 2013; van Eck, Waltman, van Raan, Klautz, \& Peul, 2013). Medical researchers voice their dissatisfaction on social media platforms that citation-based metrics for assessing research impact should be eradicated as the majority of the publications receive no citations (Cabrera, Roy, \& Chisolm, 2018).

Breast Cancer is commonly diagnosed among females, affecting 2.1 million of them every year and tops the chart in cancer-related deaths among females. As in 2018, breast cancer constitutes $15 \%$ of all the cancer deaths among females and these rates are rising around the globe constantly (World Health Organization, 2019). Despite huge advancements in the field of breast cancer, the quest for a healing treatment is still enduring (Uysal, 2017) and initial detection is vital in improving survival rates (World Health Organization, 2019).

Citations and peer review can be treated only as a partial indicator for assessing scholarly publications (Martin \& Irvine, 1983) and a single metric cannot evaluate the full impact of research (Bollen, Van de Sompel, Hagberg, \& Chute, 2009). These shortcomings of citation-based metrics have 
called for "multi-metric approach" for research assessment (Ronald \& Fred, 2013) by informing innovative, extensive and faster measures intended at supporting citation-based metrics (Priem, Piwowar, \& Hemminger, 2012). These limitations have made the publishers lookout for altmetrics as citations fail to assess the impact of recent research (Adie \& Roe, 2013; Priem \& Hemminger, 2010). In order to meet the demand, the stakeholders are promoting their research through social media platforms to reach a wider audience (Maggio, Meyer, \& Artino, 2017). Altmetrics otherwise known as alternate metrics is based on unconventional methods of assessing research impact (Torres-Salinas, Cabezas-Clavijo, \& Jiménez-Contreras, 2013), such as examining the immediacy and visibility of research publications in online platforms (Priem, Taraborelli, Groth, \& Neylon, 2010).

Research publications mentioned on social media platforms help the publishers in marketing their research publications and they also use some altmetrics tracking websites such as altmertic.com and impactsotry.org (Thelwall, Haustein, Larivière, \& Sugimoto, 2013). There are numerous benefits in using altmetrics in place of citation-based metrics (Amath, Ambacher, Leddy, Wood, \& Ramnanan, 2017) as they offer immediate impact (Thelwall et al., 2013) and mainly doesn't disregard the notion of pure readers, who read the article without citing them (Price \& Gursey, 1976; Tenopir \& King, 2000). The impact of the research on the society may also be assessed by altmetrics indicators as they fall outside the scope of science (Bornmann, 2013). The application of altmetrics in assessing scholarly communications brings out the following queries: how altmetrics and citations are measured, the relationship between citation counts and altmetrics attention and whether the quality of the publication is measured by altmetrics (Thelwall et al., 2013).

This paper aims at supporting the aforesaid argument by analyzing the highly cited articles in the field of breast cancer published in the year 2014. This study precisely pursues the answer to the following research question: is there any correlation between Citation Count and Altmetrics Attention Score? 
Despite the ongoing debates to consider altmetrics as a replacement for citation-based metrics, the actual intention of the developers of altmetrics was to complement citation based metrics instead of eliminating the latter (Altmetric.com, 2020c). Moreover, the results are interesting when both these indicators are applied to assess the impact of scientific research. Numerous advantages are seen while combining these two metrics, especially while correlating them. The correlation assessment of altmetrics and citation-based metrics will help in determining their interchangeable measures of research impact, which is a significant limitation in using only one of the indicators (Nocera, Boyd, Boudreau, Hakim, \& Rais-Bahrami, 2019). The correlation assessment of these conventional and modern metrics will exhibit the admiration of digital media (Warren, Patel, \& Boyd, 2020). The web presence of a publication can be assessed by the Altmetric Attention Score (Barakat et al., 2019). Altmetric has the ability to precisely identify the top cited publications when the analysis is broader and comprehensive (Repiso, Castillo-Esparcia, \& Torres-Salinas, 2019). Moreover, there are quite a few altmetrics studies related to cancer research (Haneef, Ravaud, Baron, Ghosn, \& Boutron, 2017; Hassona, Qutachi, Dardas, Alrashdan, \& Sawair, 2019) and numerous studies examining the correlation between altmetrics scores and citations in medical and surgical research (Barbic, Tubman, Lam, \& Barbic, 2016; Rhee, 2015; Scarlat, Mavrogenis, Pećina, \& Niculescu, 2015). Hence, the present study was carried out, based on the aforesaid advantages of combining both the indices for measuring scientific impact and also based on our best knowledge that no prior studies have analyzed the correlation between altmetrics scores and citations in breast cancer research.

\section{Research Objectives}

The objective of this study is to identify the correlations between the Citation Count and Altmetrics Attention Score (AAS) based on the top 100 highly cited articles available in the Web of Science database.

\section{Literature Review}

Usage of non-citation metrics to evaluate research impact is not unique (Thelwall et al., 2013) as various indices have been proposed to measure the research impact mentioned in Twitter, Facebook, Wikipedia, Mendeley and 
blogs (Priem \& Hemminger, 2010). Several studies have investigated the association between altmetrics and citation-based metrics. Analyzing the tweets of several arXiv articles revealed an association with citation counts (Shuai, Pepe, \& Bollen, 2012). Furthermore, the tweets of the publications of the Journal of American Medical Internet Research in the current year can help in predicting the citation counts (Eysenbach, 2011). Publications in the field of urology have shown a positive correlation with Twitter, which indicates that tweets might prove to be an early indicator in assessing the impact of a urology research publication (Hayon et al., 2019). In assessing the usage of journals, it was argued that there is no relationship between journal impact factor and electronic usage but the latter can replace the conventional ways of ascertaining the usage data (Duy \& Vaughan, 2006). A positive correlation between Mendeley readership and citation counts was identified in all the fields of study, but the strong association was seen especially in hard sciences and low association in humanities (Mohammadi \& Thelwall, 2013). Mentions in blogs and news outlets have a robust correlation as compared to other altmetrics indicators (Costas, Zahedi, \& Wouters, 2015).

A study on PLOS one journal revealed that apart from Twitter other altmetrics attentions have a positive correlation with citations (Syamili \& Rekha, 2017). Altmetrics measures to evaluate humanities research publications showed similar problems while applying bibliometrics measures to humanities like the prominence of non-journal publications, coverage of non-English language publications, etc. Digitization and globalization of humanities research, open access movements and diversification of altmetrics methods would make altmetrics superior to traditional bibliometrics methods (Hammarfelt, 2014). Comparing altmetrics with traditional metrics on the publications of medical education journals revealed that Mendeley downloads had a strong correlation with readership and citations, thereby showing potential to complement citation based metrics (Amath et al., 2017). The mentions of Health Professions Education research publications are higher in Mendeley, Twitter and Facebook which has prompted for the examination of other unused altmetrics outlets (Maggio et al., 2017). Similarly, it has been proven that altmetrics have a relationship 
with traditional bibliometrics indicators in diverse academic disciplines (Costas et al., 2015; Eysenbach, 2011).

Citation analysis of library science literature highlighted the prominent topics for improving collection development in academic institutions (Weerasinghe, 2017). Citation and altmetric analysis of research data repositories exhibited disciplinary differences in the obtainability and extent of altmetrics scores (Peters, Kraker, Lex, Gumpenberger, \& Gorraiz, 2016). The highly cited publications in the Internet of Things (IoT) revealed that computer science and telecommunication were the prominent research topics (Jayasekara \& Abu, 2018). Comparative analysis of the relationship between the citations and online attention in medical literature highlighted weak correlations and diverse predictors which may affect editorial decisions (Chapa, Haq, \& Cifu, 2017). The relationship between significant tweeters and highly cited articles discovered that the significant tweeters exhibited high competency in discriminating top cited and non-top cited articles (Hassan et al., 2019). Connectivity between altmetrics and bibliometrics indicators across academic social networking sites revealed weak correlations and also highlighted the fact that bibliometrics measures are more stable than altmetrics (Ortega, 2015). Mendeley readership and citations have a similar impact on scientific assessment yet they cannot be considered as equivalent indicators (Zahedi \& Haustein, 2018).

\section{Methodology}

Zahedi et al. (2014) recognized that the large majority of articles with high Altmetrics Attention Scores are from the Medical and Life Sciences field. Moreover, according to the World Health Organization (2019), breast cancer caused $15 \%$ of all cancer related deaths among females. As a result, breast cancer research output is one of the predominant research areas among the medical and life sciences. Hence, research publications on 'breast cancer' were selected as the target area. A study conducted by Tahamtan, Safipour Afshar, \& Ahamdzadeh (2016) identified the quality of paper; novelty and interest of subject; document type; age of paper; and accessibility and visibility of papers as paper related factors which affects the citation count. Accordingly, researches decided to consider open access journal articles published five years prior. Consequently, the "breast cancer" related open 
access journal articles that were published in 2014 were selected as the target population of this study.

\section{Citation data collection}

The Web of Science (WoS) Core Collection which includes Science Citation Index Expanded (SCI-Expanded), Social Science Citation Index (SSCI), Arts $\&$ Humanities Citation Index (A\&HCI) citation database was used to identify the research articles with the highest citation count in breast cancer and to collect bibliographic information and citation count. The WoS database allows users to customize their searching, filter their search results and download only relevant information in different formats such as plain text, HTML, EndNote and Excel. Hence, WoS database provides a very easy and flexible platform for researchers to extract bibliographic information and citation data.

The keyword "Breast Cancer" was used as the search phrase. To get the most relevant search result, the 'tittle' field within a record was used. The search query was limited to open access articles as these have more readability. Only articles published in the year 2014 were searched using refine search options under document type. The following search strategy was used to search the WoS database.

TITLE: (“Breast Cancer"); Refined by: Open Access: (OPEN ACCESS) AND PUBLICATION YEARS: (2014) AND DOCUMENT TYPES: (ARTICLE); Indexes: SCI-EXPANDED, SSCI, A\&HCI

Figure 1. Search strategy used to search Web of Science database

The database was accessed on $04^{\text {th }}$ October 2019. The above search strategy provided 3572 number of articles as the search results. These results were arranged according to the times cited from highest to lowest using the WoS 'Sort by' options. Only the details of the top 500 highly cited articles were downloaded in plain text format. Then the downloaded data was opened using Microsoft Excel and articles were ranked according to the citation count. The articles within the top 100 rankings according to the citation count were selected as the sample of this study. Accordingly, there were 104 articles within the top 100 rankings according to the citation count. All 104 
articles were considered in this study. The following information of each article was extracted from WoS database; title, journal, times cited, DOI in plain text format.

\section{Altmetrics data collection}

The 'Altmetric Bookmarklet' was used to collect Altmetrics Attention Scores (AAS) of selected articles. It is a free tool created by Altmertic.com that can be used to extract altmetrics data from the databases which are tracking by Altmetric.com. However, to extract data, the altmetrics bookmarklet needs three things; a research output, an identifier such as Digital Object Identifier (DOI) or PubMedID, etc. and it has to be mentioned in a source that Altmetric.com tracks (Altmetric.com, 2020a).

In this study, the Altmetric bookmarklet was used to extract data using the Digital Object Identifier (DOI). The DOIs of the selected publications were extracted from the WoS database. Citation count and Altmetrics Attention Score are values updating frequently. Hence, to remain the consistency, the altmetrics data were also collected on $04^{\text {th }}$ October 2019. The Altmetrics Attention Scores of selected articles were manually extracted using the altmetrics bookmarklet.

\section{Analysis}

To date, various statistical analyses have been used to measure the correlation between citation count and the Altmetrics Attention Score. Among those statistical analyses, Costas et al., 2015; Huang, Wang, \& Wu, 2018; and Ouchi, Saberi, Ansari, Hashempour, \& Isfandyari-Moghaddam, 2019 have used Spearman's rank order correlation coefficient to measure the correlation between citation count and the Altmetrics Attention Score. Spearman's rank order correlation coefficient is a non-parametric statistical test that measures "the strength and direction of association that exists between two variables measured on at least an ordinal scale" (Laerd Statistics, 2018b). Furthermore, it can be used to measure the strength and the correlation between the two ranked variables (Laerd Statistics, 2018a). Hence, in this study, Spearman's rank order correlation coefficient was used to identify the relationship between citation count and Altmetrics Attention Score. Data were analyzed using SPSS 20 software and Microsoft Excel. 


\section{Results and Discussion}

Figure 2 demonstrates the citation count of selected articles. The citation counts were varying from the range of 1142 to 100 . The article titled 'Breast Cancer Statistics, 2013' published in CA: A Cancer Journal for Clinicians (DOI: 10.3322/caac.21203) obtained the highest citation count (1142) followed by 'Effect of radiotherapy after mastectomy and axillary surgery on 10-year recurrence and 20-year breast cancer mortality: meta-analysis of individual patient data for 8135 women in 22 randomised trials' published in a journal called The Lancet (citation count - 726) (DOI: 10.1016/S01406736(14)60488-8).

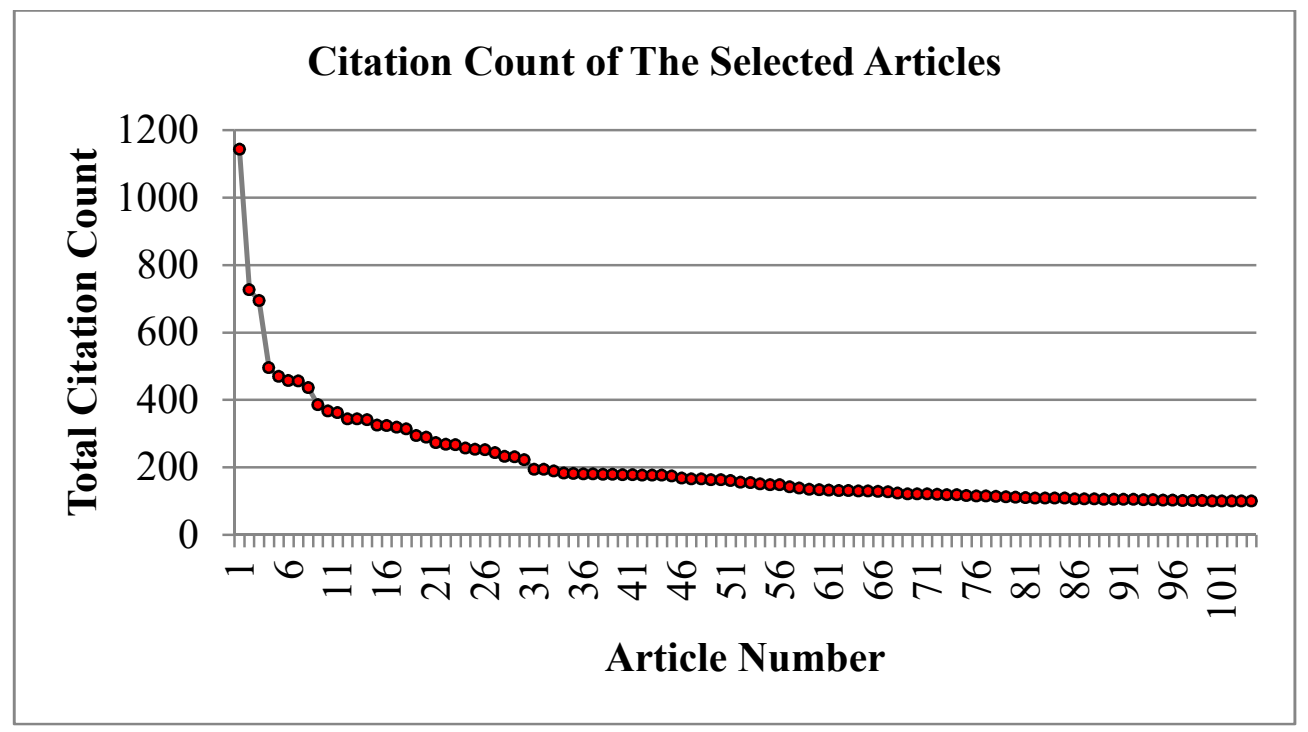

Figure 2. Citation count of the selected articles

Table 1 illustrates the top sources of publication. The selected articles were published in 60 journals. Journal of Clinical Oncology had the highest number of top cited articles (10 out of 104) followed by Annals of Oncology and Oncotarget with 8 and 5 articles respectively.

Table 1. Top sources of publication

\begin{tabular}{lc}
\hline \multicolumn{1}{c}{ Source } & $\begin{array}{c}\text { No. of } \\
\text { articles }\end{array}$ \\
\hline Journal of Clinical Oncology & 10 \\
Annals of Oncology & 8 \\
\hline
\end{tabular}




\begin{tabular}{lc}
\hline Oncotarget & 5 \\
PLOS ONE & 5 \\
Breast Cancer Research & 4 \\
British Journal of Cancer & 4 \\
Clinical Cancer Research & 4 \\
Proceedings of The National Academy of Sciences of & 4 \\
The United States of America & \\
Cancer Cell & 3 \\
Journal of Clinical Investigation & 3 \\
The Lancet & 3 \\
Oncogene & 3 \\
Other & 48 \\
\hline
\end{tabular}

Figure 3 shows the Altmetrics Attention Scores of selected articles. The Altmetrics Attention Scores were varying from 1091 to zero. The article titled 'Breast Cancer Screening Using Tomosynthesis in Combination with Digital Mammography' published in Journal of the American Medical Association (DOI: 10.1001/jama.2014.6095) obtained the highest Altmetrics Attention Score (AAS - 1091) followed by the article titled 'Twenty five year follow-up for breast cancer incidence and mortality of the Canadian National Breast Screening Study: randomised screening trial' (AAS - 871). There are nine articles with zero Altmetrics Attention Score (Table 4). Altmetric bookmarklet is displaying the following message for articles with zero Altmetrics Attention Score; 'Altmetric hasn't picked up any sharing activity around this article yet'.

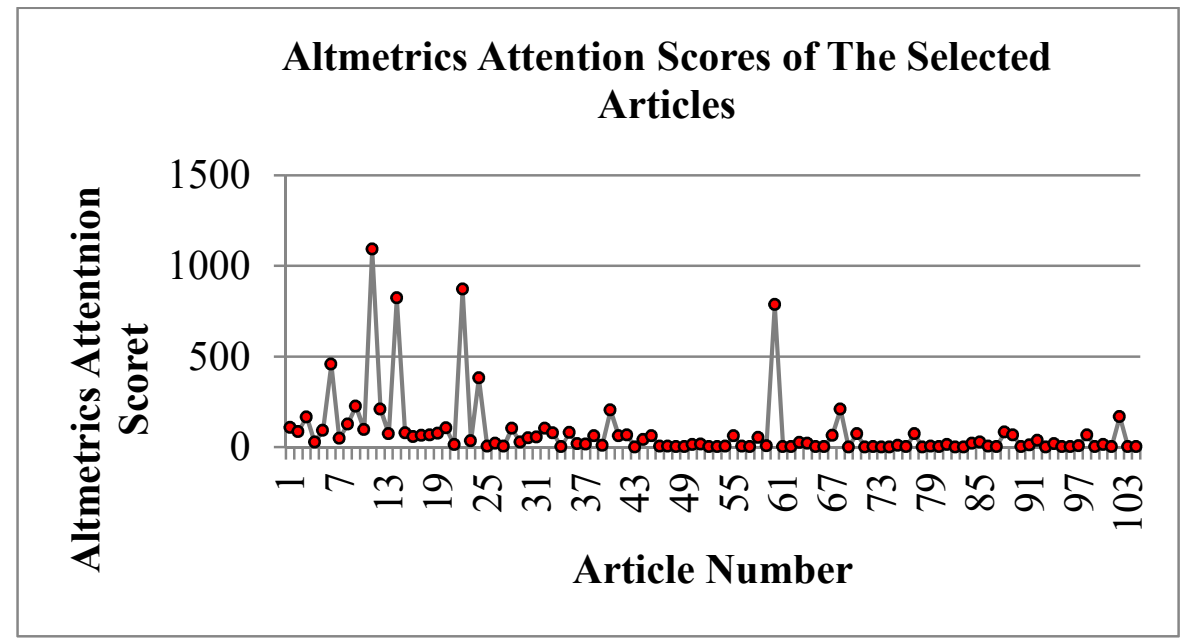

Figure 3. Altmetrics attention scores of the selected articles 
Table 2 demonstrates the top 10 articles with the highest citation count and their respective Altmetrics Attention Scores, citation count ranks and AAS ranks. Furthermore, table 3 illustrates the top 10 articles with the highest Altmetrics Attention Score and their respective citation counts, citation count rank and AAS ranks

Table 2 Top 10 articles with the highest citation count

\begin{tabular}{|c|c|c|c|c|}
\hline Title & $\begin{array}{c}\text { Citation } \\
\text { Count }\end{array}$ & $\begin{array}{c}\text { Altmetric } \\
\text { Attention } \\
\text { Score }\end{array}$ & $\begin{array}{c}\mathrm{CC} \\
\text { Rank }\end{array}$ & $\begin{array}{l}\text { AAS } \\
\text { Rank }\end{array}$ \\
\hline Breast Cancer Statistics, 2013 & 1142 & 107 & 1 & 2 \\
\hline $\begin{array}{l}\text { Effect of radiotherapy after mastectomy } \\
\text { and axillary surgery on } 10 \text {-year } \\
\text { recurrence and } 20 \text {-year breast cancer } \\
\text { mortality: meta-analysis of individual } \\
\text { patient data for } 8135 \text { women in } 22 \\
\text { randomised trials }\end{array}$ & 726 & 85 & 2 & 20 \\
\hline $\begin{array}{l}\text { Circulating Tumor Cell Clusters Are } \\
\text { Oligoclonal Precursors of Breast Cancer } \\
\text { Metastasis }\end{array}$ & 694 & 166 & 3 & 13 \\
\hline $\begin{array}{l}\text { Tumor infiltrating lymphocytes are } \\
\text { prognostic in triple negative breast } \\
\text { cancer and predictive for trastuzumab } \\
\text { benefit in early breast cancer: results } \\
\text { from the FinHER trial }\end{array}$ & 495 & 27 & 4 & 48 \\
\hline $\begin{array}{l}\text { Radiotherapy or surgery of the axilla } \\
\text { after a positive sentinel node in breast } \\
\text { cancer (EORTC 10981-22023 } \\
\text { AMAROS): a randomised, multicentre, } \\
\text { open-label, phase } 3 \text { non-inferiority trial }\end{array}$ & 469 & 91 & 5 & 19 \\
\hline $\begin{array}{l}\text { Recommendations for Human Epidermal } \\
\text { Growth Factor Receptor } 2 \text { Testing in } \\
\text { Breast Cancer American Society of } \\
\text { Clinical Oncology/College of American } \\
\text { Pathologists Clinical Practice Guideline } \\
\text { Update }\end{array}$ & 457 & 457 & 6 & 6 \\
\hline $\begin{array}{l}\text { Prognostic Value of Tumor-Infiltrating } \\
\text { Lymphocytes in Triple-Negative Breast } \\
\text { Cancers From Two Phase III }\end{array}$ & 456 & 47 & 7 & 43 \\
\hline
\end{tabular}


Randomized Adjuvant Breast Cancer

Trials: ECOG 2197 and ECOG 1199

Clonal evolution in breast cancer

436

125

8

14

revealed by single nucleus genome

sequencing

Risk-adapted targeted intraoperative

385

226

$9 \quad 8$

radiotherapy versus whole-breast

radiotherapy for breast cancer: 5-year

results for local control and overall

survival from the TARGIT-A

randomised trial

Adjuvant Endocrine Therapy for Women

367

96

10

18

With Hormone Receptor-Positive Breast

Cancer: American Society of Clinical

Oncology Clinical Practice Guideline

Focused Update

Table 3. Top 10 articles with the highest Altmetric Attention Score

\begin{tabular}{lcccc}
\hline \multicolumn{1}{c}{ Title } & $\begin{array}{c}\text { Altmetric } \\
\text { Attention } \\
\text { Score }\end{array}$ & $\begin{array}{c}\text { Citation } \\
\text { Count }\end{array}$ & $\begin{array}{c}\text { AAS } \\
\text { Rank }\end{array}$ & $\begin{array}{c}\text { CC } \\
\text { Rank }\end{array}$ \\
\hline $\begin{array}{l}\text { Breast Cancer Screening Using } \\
\text { Tomosynthesis in Combination With }\end{array}$ & 1091 & 362 & 1 & 11 \\
$\begin{array}{l}\text { Digital Mammography } \\
\text { Twenty five year follow-up for breast } \\
\text { cancer incidence and mortality of the }\end{array}$ & 871 & 268 & 2 & 22 \\
$\begin{array}{l}\text { Canadian National Breast Screening Study: } \\
\text { randomised screening trial }\end{array}$ & & & & \\
$\begin{array}{l}\text { Breast-Cancer Risk in Families with } \\
\text { Mutations in PALB2 }\end{array}$ & 822 & 341 & 3 & 14 \\
Use of and Mortality After Bilateral & 786 & 133 & 4 & 60 \\
$\begin{array}{l}\text { Mastectomy Compared With Other } \\
\text { Surgical Treatments for Breast Cancer in }\end{array}$ & & & & \\
$\begin{array}{l}\text { California, 1998-2011 } \\
\text { Recommendations for Human Epidermal } \\
\text { Growth Factor Receptor 2 Testing in } \\
\text { Breast Cancer American Society of } \\
\text { Clinical Oncology/College of American }\end{array}$ & 457 & 457 & 5 & 6 \\
Pathologists Clinical Practice Guideline & & & & \\
\hline
\end{tabular}




\begin{tabular}{lllll}
\hline $\begin{array}{l}\text { Update } \\
\text { Anastrozole for prevention of breast cancer } \\
\text { in high-risk postmenopausal women (IBIS- }\end{array}$ & 381 & 257 & 6 & 24 \\
$\begin{array}{l}\text { II): an international, double-blind, } \\
\text { randomised placebo-controlled trial }\end{array}$ & & & & \\
$\begin{array}{l}\text { Risk-adapted targeted intraoperative } \\
\text { radiotherapy versus whole-breast } \\
\text { radiotherapy for breast cancer: 5-year } \\
\text { results for local control and overall survival } \\
\text { from the TARGIT-A randomised trial }\end{array}$ & 226 & 385 & 7 & 9 \\
$\begin{array}{l}\text { Adjuvant Exemestane with Ovarian } \\
\text { Suppression in Premenopausal Breast }\end{array}$ & 210 & 343 & 8 & 12 \\
$\begin{array}{l}\text { Cancer } \\
\text { Breast Cancer and Circadian Disruption }\end{array}$ & 208 & 123 & 9 & 68 \\
$\begin{array}{l}\text { From Electric Lighting in the Modern } \\
\text { World }\end{array}$ & & & & \\
$\begin{array}{l}\text { Trends and Variation in Use of Breast } \\
\text { Reconstruction in Patients With Breast }\end{array}$ & 204 & 178 & 10 & 40 \\
$\begin{array}{l}\text { Cancer Undergoing Mastectomy in the } \\
\text { United States }\end{array}$ & & & & \\
\hline
\end{tabular}

Table 4. Articles with zero Altmetrics Attention Score

\begin{tabular}{lccc}
\multicolumn{1}{c}{ Title } & $\begin{array}{c}\text { Citation } \\
\text { Count }\end{array}$ & $\begin{array}{c}\text { CC } \\
\text { Rank }\end{array}$ & $\begin{array}{c}\text { Altmetric } \\
\text { Attention } \\
\text { Score }\end{array}$ \\
\hline $\begin{array}{l}\text { Cancer-associated fibroblasts induce epithelial- } \\
\text { mesenchymal transition of breast cancer cells } \\
\text { through paracrine TGF-beta signalling }\end{array}$ & 176 & 42 & 0 \\
$\begin{array}{l}\text { Tumor cell-produced matrix metalloproteinase } \\
\text { (MMP-9) drives malignant progression and }\end{array}$ & 121 & 69 & 0 \\
$\begin{array}{l}\text { metastasis of basal-like triple negative breast } \\
\text { cancer }\end{array}$ & & & \\
$\begin{array}{l}\text { Breast Cancer Version 3.2014 Clinical Practice } \\
\text { Guidelines in Oncology }\end{array}$ & 120 & 70 & 0 \\
$\begin{array}{l}\text { MicroRNA-25 regulates chemoresistance- } \\
\text { associated autophagy in breast cancer cells, a } \\
\text { process modulated by the natural autophagy }\end{array}$ & 118 & 73 & 0 \\
inducer isoliquiritigenin & & & \\
Deregulation of the & 118 & 73 & 0 \\
\hline
\end{tabular}


EGFR/PI3K/PTEN/Akt/mTORC1 pathway in

breast cancer: possibilities for therapeutic

intervention

PD-L1 Expression Is Increased in a Subset of

Basal Type Breast Cancer Cells

Computer-aided detection of breast cancer on

mammograms: A swarm intelligence optimized

113

108

108

The elevated preoperative platelet-to-lymphocyte

ratio predicts poor prognosis in breast cancer

patients

The Transcriptional Regulators TAZ and YAP

Direct Transforming Growth Factor beta-induced

Tumorigenic Phenotypes in Breast Cancer Cells

Figure 4 illustrates the outcome of Spearman's rank order correlation coefficient which was run to determine the relationship between citation count and Altmetrics Attention Score. There is a positive correlation between citation count and Altmetrics Attention Score, which is statistically significant $\left(\mathrm{r}_{\mathrm{s}}=.552, \mathrm{p}<0.01\right)$.

\begin{tabular}{|c|c|c|c|c|}
\hline \multicolumn{3}{|c|}{ Correlations } & $\begin{array}{l}\text { AAS } \\
\text { Rank }\end{array}$ & $\begin{array}{c}\text { TC } \\
\text { Rank }\end{array}$ \\
\hline \multirow{6}{*}{ Spearman's rho } & & Correlation Coefficient & 1.000 & $.552^{* *}$ \\
\hline & AAS Ran & Sig. (2-tailed) & & .000 \\
\hline & & $\mathrm{N}$ & 104 & 104 \\
\hline & & Correlation Coefficient & $.552^{* *}$ & 1.000 \\
\hline & TC Rank & Sig. (2-tailed) & .000 & \\
\hline & & $\mathrm{N}$ & 104 & 104 \\
\hline
\end{tabular}

**. Correlation is significant at the 0.01 level (2-tailed).

Figure 4. Results of Spearman's rank order correlation coefficient

\section{Conclusion}

This study focused on the correlations between the Citation Count and Altmetrics Attention Score (AAS) based on the top 100 highly cited articles on breast cancer available in the Web of Science database. The results showed that, citation counts of the selected articles were varying from 1142 
to 100. Meanwhile, the Altmetrics Attention Scores were varying from 1091 to zero.

According to the results of this study, there is a positive correlation $\left(\mathrm{r}_{\mathrm{s}}=\right.$ $.552, \mathrm{p}<0.01)$ between the citation count and the Altmetrics Attention Score. This finding matches with those observed in earlier studies. Furthermore, this finding is in agreement with a study conducted by Syamili \& Rekha (2017) which showed altmetrics attentions have a positive correlation with citations. Researchers can further investigate the correlation between citation count and Altmetrics Attention Score in other disciplines.

As mentioned in the literature review, some researchers have revealed that citation count has an association between numbers of tweets received (Eysenbach, 2011; Hayon et al., 2019; Shuai et al., 2012); Mendeley readership (Hammarfelt, 2014; Mohammadi \& Thelwall, 2013) and mentions in blogs and news outlets (Costas et al., 2015). Altmetric Attention Score is a combination of attentions a publication received through so many online platforms including blogs, online reference managers, social media, post publication peer-review platforms and many more (Altmetric.com, 2020b). As a result, researchers can conduct future research focusing on the association between the attention received via a specific online platform and the citation count.

\section{References}

Adie, E., \& Roe, W. (2013). Altmetric: Enriching scholarly content with article-leveldiscussion and metrics. Learned Publishing. https://doi.org /10. $1087 / 20130103$

Altmetric.com. (2020a). How it works - Altmetric. Retrieved June 2, 2020, from https://www.altmetric.com/about-our-data/how-it-works/

Altmetric.com. (2020b). Our sources. Retrieved June 3, 2020, from https:// www.altmetric.com/about-our-data/our-sources/

Altmetric.com. (2020c). What are Altmetrics? Retrieved February 15, 2020, from https://www.altmetric.com/about-altmetrics/what-are-altm etrics/ 
Amath, A., Ambacher, K., Leddy, J. J., Wood, T. J., \& Ramnanan, C. J. (2017). Comparing alternative and traditional dissemination metrics in medical education. Medical Education. https://doi.org/ 10.1111/medu .13359

Barakat, A. F., Nimri, N., Shokr, M., Mahtta, D., Mansoor, H., Masri, A., \& Elgendy, I. Y. (2019). Correlation of Altmetric Attention Score and Citations for High-Impact General Medicine Journals: a Cross-sectional Study. Journal of General Internal Medicine. https://doi.org/10.1007/ s11606-01904838-6

Barbic, D., Tubman, M., Lam, H., \& Barbic, S. (2016). An Analysis of Altmetrics in Emergency Medicine. Academic Emergency Medicine. https://doi.org/10.1111/acem.12898

Bollen, J., Van de Sompel, H., Hagberg, A., \& Chute, R. (2009). A principal component analysis of 39 scientific impact measures. PLOS ONE. https://doi.org/10.1371/journal.pone.0006022

Bornmann, L. (2013). What is societal impact of research and how can it be assessed? a literature survey. Journal of the American Society for Information Science and Technology. https://doi.org/10.1002/asi.22803

Bornmann, L., \& Leydesdorff, L. (2013). The validation of (advanced) bibliometric indicators through peer assessments: A comparative study using data from InCites and F1000. Journal of Informetrics, 7(2), 286-291. https://doi.org/10.1016/j.joi.2012.12.003

Cabrera, D., Roy, D., \& Chisolm, M. S. (2018). Social Media Scholarship and Alternative Metrics for Academic Promotion and Tenure. Journal of the American College of Radiology. https://doi.org/10.1016/j.jacr.2017.09.012

Chapa, J., Haq, Z., \& Cifu, A. S. (2017). Comparative analysis of the factors associated with citation and media coverage of clinical research. Scientometrics. https://doi.org/10.1007/s11192-017-2428-5 
Costas, R., Zahedi, Z., \& Wouters, P. (2015). Do "altmetrics" correlate with citations? Extensive comparison of altmetric indicators with citations from a multidisciplinary perspective. Journal of the Association for Information Science and Technology, 66(10), 2003-2019. https://doi.org/10.1002/asi. 23309

Duy, J., \& Vaughan, L. (2006). Can electronic journal usage data replace citation data as a measure of journal use? An empirical examination1. Journal of Academic Librarianship. https://doi.org/10.1016/j.acalib.2006 .05 .005

Eysenbach, G. (2011). Can tweets predict citations? Metrics of social impact based on Twitter and correlation with traditional metrics of scientific impact. Journal of Medical Internet Research. https://doi.org/10.2196/jmir.2012

Fenner, M. (2013). What Can Article-Level Metrics Do for You? PLoS Biology. https://doi.org/10.1371/journal.pbio.1001687

Hammarfelt, B. (2014). Using altmetrics for assessing research impact in the humanities. Scientometrics, 101(2), 1419-1430. https://doi.org/10. 1007/s11 192-014-1261-3

Haneef, R., Ravaud, P., Baron, G., Ghosn, L., \& Boutron, I. (2017). Factors associated with online media attention to research: a cohort study of articles evaluating cancer treatments. Research Integrity and Peer Review. https://doi.org/10.1186/s41073-017-0033-z

Hassan, S. U., Bowman, T. D., Shabbir, M., Akhtar, A., Imran, M., \& Aljohani, N. R. (2019). Influential tweeters in relation to highly cited articles in altmetric big data. Scientometrics. https://doi.org/10.1007/ s11192-01903044-9

Hassona, Y., Qutachi, T., Dardas, L., Alrashdan, M. S., \& Sawair, F. (2019). The online attention to oral cancer research: An Altmetric analysis. Oral Diseases. https://doi.org/10.1111/odi.13111 
Hayon, S., Tripathi, H., Stormont, I. M., Dunne, M. M., Naslund, M. J., \& Siddiqui, M. M. (2019). Twitter Mentions and Academic Citations in the Urologic Literature. Urology. https://doi.org/10.1016/j.urology. 2018.08.041

Huang, W., Wang, P., \& Wu, Q. (2018). A correlation comparison between Altmetric Attention Scores and citations for six PLOS journals. PLoS ONE, 13(4), 1-15. https://doi.org/10.1371/journal.pone.0194962

Jayasekara, P. K., \& Abu, K. S. (2018). Top Fifty Highly Cited Publications on the Internet of Things. Journal of the University Librarians Association of Sri Lanka, 21(2), 140. https://doi.org/10.4038/ jula.v21i2.7922

Laerd Statistics. (2018a). Spearman's Rank-Order Correlation. Retrieved June 3, 2020, from https://statistics.laerd.com/statistical-guides/ spear mansrank-order-correlation-statistical-guide.php

Laerd Statistics. (2018b). Spearman's Rank Order Correlation using SPSS Statistics. Retrieved June 3, 2020, from A How-To Statistical Guide by Laerd Statistics website: https://statistics.laerd.com/spss-tutorials/spearmansrank-order-correlation-using-spss-statistics.php

Maggio, L. A., Meyer, H. S., \& Artino, A. R. (2017). Beyond Citation Rates: A Real-Time Impact Analysis of Health Professions Education Research Using Altmetrics. Academic Medicine. https://doi.org/10.1097/ ACM. 0000000000001897

Martin, B. R., \& Irvine, J. (1983). Assessing basic research. Some partial indicators of scientific progress in radio astronomy. Research Policy. https://doi.org/10.1016/0048-7333(83)90005-7

Melero, R. (2015). Altmetrics - A complement to conventional metrics. Bioc hemia Medica. https://doi.org/10.11613/BM.2015.016

Mohammadi, E., \& Thelwall, M. (2013). Assessing the mendeley readership of social sciences and humanities research. Proceedings of ISSI $2013-14$ th International Society of Scientometrics and Informetrics Conference. 
Nocera, A. P., Boyd, C. J., Boudreau, H., Hakim, O., \& Rais-Bahrami, S. (2019). Examining the Correlation Between Altmetric Score and Citations in the Urology Literature. Urology. https://doi.org/10.1016 /j.urology.2019. 09.014

Ortega, J. L. (2015). Relationship between altmetric and bibliometric indicators across academic social sites: The case of CSIC's members. Journal of Informetrics, 9(1), 39-49. https://doi.org/10.1016/j.joi. 2014 .11 .004

Ouchi, A., Saberi, M. K., Ansari, N., Hashempour, L., \& IsfandyariMoghaddam, A. (2019). Do altmetrics correlate with citations? A study based on the 1,000 most-cited articles. Information Discovery and Delivery, 47(4), 192-202. https://doi.org/10.1108/IDD-07-2019-0050

Peters, I., Kraker, P., Lex, E., Gumpenberger, C., \& Gorraiz, J. (2016). Research data explored: an extended analysis of citations and altmetrics. Scientometrics. https://doi.org/10.1007/s11192-016-1887-4

Price, D. S., \& Gursey, S. (1976). Studies in scientometrics, Part I: Transience and continuance in scientific authorship. International Forum for Information and Documentation. https://doi.org/10.1007/s11434-013-5939-3

Priem, J., \& Hemminger, B. M. (2010). Scientometrics 2.0: Toward new metrics of scholarly impact on the social Web. First Monday, 15, http://frodo.lib.uic.edu/ojsjournals/index.php/fm/. https://doi.org/10.5210 /fm. v15i7.2874

Priem, J., Piwowar, H. A., \& Hemminger, B. M. (2012). Altmetrics in the wild: Using social media to explore scholarly impact. Retrieved from http://arxiv.org/abs/1203.4745

Priem, J., Taraborelli, D., Groth, P., \& Neylon, C. (2010). Altmetrics: A Manifesto. 
Repiso, R., Castillo-Esparcia, A., \& Torres-Salinas, D. (2019). Altmetrics, alternative indicators for Web of Science Communication studies journals. Scientometrics. https://doi.org/10.1007/s11192-019-03070-7

Rhee, J. S. (2015). High-impact articles-citations, downloads, and altmetric score. JAMA Facial Plastic Surgery. https://doi.org/10.1001/jamafacial .2015 .0869

Ronald, R., \& Fred, Y. Y. (2013). A multi-metric approach for research evaluation. Chinese Science Bulletin. https://doi.org/10.1007/s11434-0135939-3

Scarlat, M. M., Mavrogenis, A. F., Pećina, M., \& Niculescu, M. (2015). Impact and alternative metrics for medical publishing: our experience with International Orthopaedics. International Orthopaedics. https://doi.org/10. 1007/s00264-015-2766-y

Shuai, X., Pepe, A., \& Bollen, J. (2012). How the Scientific Community Reacts to Newly Submitted Preprints: Article Downloads, Twitter Mentions, and Citations. PLoS ONE. https://doi.org/10.1371/journal.pone.0047523

Syamili, C., \& Rekha, R. V. (2017). Do altmetric correlate with citation? : A study based on PLOS ONE journal. COLLNET Journal of Scientometrics and Information Management, 11(1), 103-117. https://doi.org/10.1080/0973 7766.2016 .1260815

Tahamtan, I., Safipour Afshar, A., \& Ahamdzadeh, K. (2016). Factors affecting number of citations: a comprehensive review of the literature. Scientometrics, 107(3), 1195-1225. https://doi.org/10.1007/s11192-016$1889-2$

Tenopir, C., \& King, D. W. (2000). Towards electronic journals : realities for scientists, librarians, and publishers. Special Libraries Association. 
Thelwall, M., Haustein, S., Larivière, V., \& Sugimoto, C. R. (2013). Do Altmetrics Work? Twitter and Ten Other Social Web Services. PLoS ONE, 8(5). https://doi.org/10.1371/journal.pone.0064841

Torres-Salinas, D., Cabezas-Clavijo, álvaro, \& Jiménez-Contreras, E. (2013). Altmetrics: New indicators for scientific communication in web 2.0. Comunicar. https://doi.org/10.3916/C41-2013-05

Trueger, N. S., Thoma, B., Hsu, C. H., Sullivan, D., Peters, L., \& Lin, M. (2015). The altmetric score: A new measure for article-level dissemination and impact. Annals of Emergency Medicine. https://doi.org/10.1016/j.annem ergmed.2015.04.022

Uysal, E. (2017). Top 100 Cited Classic Articles in Breast Cancer Research. European Journal of Breast Health. https://doi.org/10.5152/ejbh.2017.3480

Van Eck, N. J., Waltman, L., Van Raan, A. F. J., Klautz, R. J. M., \& Peul, W. C. (2013). Citation Analysis May Severely Underestimate the Impact of Clinical Research as Compared to Basic Research. PLoS ONE. https://doi.org/10.1371/journal.pone.0062395

Warren, V. T., Patel, B., \& Boyd, C. J. (2020). Analyzing the relationship between Altmetric score and literature citations in the Implantology literature. Clinical Implant Dentistry and Related Research, 22(1), 54-58. https://doi.org/10.1111/cid.12876

Weerasinghe, S. (2017). Citation Analysis of Library and Information Science research output for collection development. Journal of the University Librarians Association of Sri Lanka. https://doi.org/10.4038/ jula.v20i1.7893

World Health Organization. (2019). Breast cancer. Retrieved April 4, 2020, from https://www.who.int/cancer/prevention/diagnosis-screening/ breast-can cer/en/ 
Zahedi, Z., Costas, R., \& Wouters, P. (2014). How well developed are altmetrics? A cross-disciplinary analysis of the presence of 'alternative metrics' in scientific publications. Scientometrics. https://doi.org/10. 1007/s11192-014-1264-0

Zahedi, Z., \& Haustein, S. (2018). On the relationships between bibliographic characteristics of scientific documents and citation and Mendeley readership counts: A large-scale analysis of Web of Science publications. Journal of Informetrics. https://doi.org/10.1016/j.joi.2017 .12 .005 